\title{
Effects of nedocromil and salbutamol on airway reactivity in children with asthma
}

\author{
A. Pfleger, E. Eber, E. Weinhandl, M.S. Zach
}

Effects of nedocromil and salbutamol on airway reactivity in children with asthma. A. Pfleger, E. Eber, E. Weinhandl, M.S. Zach. C ERS Journals Ltd 2002.

ABSTRACT: Nedocromil and salbutamol are effective drugs in preventing exerciseinduced asthma (EIA). The aim of this study was to compare the protective effects of both drugs and a combination of both drugs against cold dry air-induced bronchoconstriction, using cold dry air challenges $(\mathrm{CACh})$ as a surrogate for exercise.

Twenty-five atopic children (mean age 13.7, range 8-18 yrs) with EIA participated in the study. Lung function tests were performed before medication, $30 \mathrm{~min}$ after medication and just before $\mathrm{CACh}$, and 3 and $15 \mathrm{~min}$ after the challenge on four consecutive days. CACh consisted of a 4-min isocapnic hyperpnoea of $-10^{\circ} \mathrm{C}$, absolutely dry air. Treatment consisted of nedocromil (two puffs of $2 \mathrm{mg}$ ) plus placebo, salbutamol (two puffs of $100 \mu \mathrm{g}$ ) plus placebo, the combination of both drugs, and placebo alone, in a random order.

Both active drugs were significantly more protective than placebo and the combination showed an additive effect. Mean maximum postchallenge decrease in forced expiratory volume in one second after placebo was $27 \pm 8.1 \%, 12 \pm 9.5 \%$ after nedocromil, $8 \pm 10.4 \%$ after salbutamol, and $4.5 \pm 6.7 \%$ after the combination of both drugs, respectively.

These results suggest that both drugs protect against exercise-induced asthma. Although not as effective as salbutamol and combined medication, nedocromil can give sufficient protection for many patients.

Eur Respir J 2002; 20: 624-629.
Respiratory and Allergic Disease Division, Paediatric Dept, University of Graz, Graz, Austria.

Correspondence: A. Pfleger, Klinische Abteilung für Pädiatrische Pulmonologie und Allergologie, Univ.-Klinik für Kinder-und Jugendheilkunde, Auenbruggerplatz 30, A-8036 Graz, Austria. Fax: 433163853276

E-mail: andreas.pfleger@kfunigraz.ac.at

Keywords: Exercise-induced asthma cold dry air challenge

nedocromil

preventive effect

salbutamol

Received: January 282002

Accepted after revision: April 162002

This study was supported by grant TIL-AT 601 from Rhône Poulenc Rorer.
Exercise-induced bronchoconstriction (EIB) is a common manifestation of bronchial asthma and is reported to occur in $40-90 \%$ of all paediatric patients $[1,2]$. The most important mechanism responsible for triggering EIB is exercise-induced hyperpnoea [3-5]. Hyperpnoea effects respiratory water loss, mucosal drying and cooling [6, 7]. Recent work has suggested that the resulting hyperosmolarity of the epithelial lining fluid may lead to regulatory volume changes of airway epithelial cells $[8,9]$. This results in the release of various bronchoconstrictive mediators from cells in the bronchial mucosa [10].

In susceptible patients, EIB is routinely prevented by inhaling a $\beta_{2}$-sympathomimetic bronchodilator before any physical exertion $[11,12]$. Nedocromil sodium may reduce EIB by interfering with regulatory volume change in response to cell shrinkage [9]. It may therefore be an alternative to sympathomimetic bronchodilators for preventing EIB in susceptible asthma patients. However, there are substantial differences in the mode of action between these two premedications. While sympathomimetics predominantly prevent constriction of bronchial smooth muscle, nedocromil modifies the triggering event, thus reducing the release of mediators into the bronchial mucosa. As these mediators may not only have bronchoconstrictive but proinflammatory effects, the routine use of nedocromil as premedication for EIB might have some theoretical long-term advantages.

These long-term advantages, however, could only be of clinical relevance if the nedocromil-effected protection against EIB is of comparable magnitude to the one offered by sympathomimetic bronchodilators. Consequently, the current authors compared nedocromil with salbutamol, placebo, and a combined medication of nedocromil and salbutamol, respectively, to assess its relative protection against hyperpnoeainduced asthma in a double-blind, placebo-controlled study. A series of cold dry air hyperpnoea challenges was used as a surrogate for repeated exercise provocations [13-15].

\section{Patients and methods}

\section{Subjects}

Twenty-five paediatric and adolescent asthma patients (10 female, 15 male), with a mean age of 13.7 yrs (SD 2.57, range 7.8-17.8) and with exerciseinduced asthma (EIA) participated in the study. Asthma was defined clinically according to the criteria of the American Thoracic Society [16]. On the basis of their history and a positive skin-prick test response to 
one or several of 16 common allergens, they were all considered atopic. The patients' long-term antiasthma treatment consisted of either inhaled budesonide $(n=13)$, beclomethasone $(n=1)$, fluticasone $(n=3)$, nedocromil sodium $(n=6)$ or sodium cromoglycate $(n=2)$. Twenty-four hours prior to the study, this topical medication was stopped. In addition, no bronchodilator medication was taken for $\geqslant 12 \mathrm{~h}$. None of the subjects had had a respiratory infection within the previous 6 weeks. Informed consent was obtained from both children and parents. The study was approved by the Ethics Committee of the Medical Faculty, University of Graz (Graz, Austria).

\section{Design}

This was a double-blind, placebo-controlled crossover study. Each cold dry air challenge (CACh) was performed at 14:00 h. To compare the protective effect with cold dry air-induced bronchoconstriction, each patient was tested after each of the following four premedications, which were given in random order on 4 consecutive days. 1) Nedocromil verum (NV) (two puffs of $2 \mathrm{mg}$ ) and salbutamol verum (SV) (two puffs of $100 \mu \mathrm{g}$ ). Both drugs were inhaled by successive

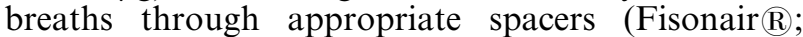
Fisons Arzneimittel GmbH, Cologne, Germany, and Volumatic $\mathbb{R}$; Glaxowellcome, Bad Oldesloe, Germany). 2) Nedocromil placebo (NP) (two puffs) and SV (two puffs of $100 \mu \mathrm{g}$ ), both administered as described above. 3) NV (two puffs of $2 \mathrm{mg}$ ) and salbutamol placebo (SP) (two puffs), both administered as described above. 4) NP (two puffs) and SP (two puffs), both administered as described above.

\section{Methods}

Pulmonary function tests (PFTs) were carried out on a pneumotachygraph spirometer (Pneumotest Junior; Jaeger, Würzburg, Germany), in accordance with standardised guidelines [17]. For each assessment, the patients performed forced vital capacity (FVC) manoeuvres, which were recorded in the form of maximum expiratory volume/time and flow/volume curves. FVC, forced expiratory volume in one second (FEV1), peak expiratory flow (PEF), maximal expiratory flow at 50\% (MEF50) and at 25\% (MEF25) of remaining $\mathrm{FVC}$ were measured. These measurements were expressed in absolute terms and in per cent of predicted normal values, as based on established reference standards [18]. PFTs were carried out as baseline measurements $30 \mathrm{~min}$ after medication, i.e. just before $\mathrm{CACh}$, and 3 and $15 \mathrm{~min}$ after $\mathrm{CACh}$.

$\mathrm{CACh}$ was performed according to an established protocol [13, 14]. Cold dry air was produced by a commercially-available heat exchanger (RHES; Jaeger). Subjects hyperventilated absolutely dry, $-10^{\circ} \mathrm{C}$ air at FEV $1 \times 22.5$ for 4 min [13-15]. This level of hyperventilation was maintained by having the subjects compete with a target balloon. A carbon dioxide $\left(\mathrm{CO}_{2}\right)$-analyser continuously monitored the $\mathrm{CO}_{2}$ concentration in the expired air, and $\mathrm{CO}_{2}$ was added to the inspired air in order to keep the subjects eucapnic.

CACh-induced lung function changes were expressed as percentage of baseline, as follows:

$$
\begin{aligned}
\Delta \mathrm{FEV}_{1}(\%)= & \left(\left(\text { pretest } \mathrm{FEV}_{1}-\text { post-test } \mathrm{FEV}_{1}\right)\right. \\
& \left./ \text { pretest } \mathrm{FEV}_{1}\right) \times 100
\end{aligned}
$$

Complete protection was considered to have been obtained when lung function changes $3 \mathrm{~min}$ after $\mathrm{CACh}$ remained within the range of normoreactivity, defined as $\triangle \mathrm{FEV} 1<-9 \%[13]$.

If the FEV1 15 min after CACh had not returned to $\geqslant 90 \%$ of the baseline value, the patient was treated with nebulised salbutamol. Such treatment was also administered when the patient felt any shortness of breath.

\section{Statistical analysis}

PFTs before and after the four premedications were compared by means of analysis of variance (ANOVA). The overall difference was tested with a repeated measurements model and post hoc multiple comparisons. The specific effect of the CACh response was defined as change in percentage from the postmedication value to the value $3 \mathrm{~min}$ after $\mathrm{CACh}$. The specific effect was also tested with ANOVA and Waller-Duncan pairwise comparisons. A p-value of 0.05 was taken as the limit of statistical significance. For simplicity's sake, only the results for FEV1 are reported. Findings for FVC, PEF, MEF50 and MEF25 are available on request.

\section{Results}

Individual baseline FEV1 measurements and CAChinduced individual changes of FEV1 after all forms of premedication are shown in table 1 .

Baseline, postmedication (pre-CACh) and post-CACh (3 and $15 \mathrm{~min}$ ) PFTs are summarised in table 2 and illustrated in figure 1. Baseline measurements did not differ between the four premedication regimens. Furthermore, there was no difference between the baseline values when analysed consecutively for the 4 study days. Both premedications containing salbutamol (NV+SV, NP+SV) effected statistically significant positive changes in FEV1. CACh caused a statistically significant decrease (postmedication to $3 \mathrm{~min}$ post$\mathrm{CACh}$ ) of pulmonary functions for all four premedication regimens. All measurements had markedly improved $15 \mathrm{~min}$ post-CACh, but still differed significantly from the postmedication values.

Table 2 also contains a cross-sectional statistical comparison of measurements. All regimens containing salbutamol $(\mathrm{NV}+\mathrm{SV}, \mathrm{NP}+\mathrm{SV})$ produced significantly better postmedication measurements than those without $(\mathrm{NV}+\mathrm{SP}, \mathrm{NP}+\mathrm{SP})$. The best lung functions $3 \mathrm{~min}$ post-CACh were observed with the combination of both active drugs $(\mathrm{NV}+\mathrm{SV})$. Post-CACh values after all other premedication regimens were significantly lower. The CACh-induced fall of lung functions after 
Table 1. - Baseline and cold dry air challenge (CACh)-induced changes in forced expiratory volume in one second (FEV 1$)$

\begin{tabular}{|c|c|c|c|c|c|c|c|}
\hline \multirow[t]{2}{*}{ Patient no. } & \multirow[t]{2}{*}{ Sex } & \multirow[t]{2}{*}{ Age yrs } & \multirow{2}{*}{$\begin{array}{c}\text { FEV1 } \\
\text { Baseline }\end{array}$} & \multicolumn{4}{|c|}{$\triangle \mathrm{FEV}_{1} \%$ preCACh } \\
\hline & & & & Placebo & Salb. & Ned. & Salb./Ned. \\
\hline 1 & M & 17.8 & 4.44 & -33.9 & -6.3 & -13.9 & -9.3 \\
\hline 2 & $\mathrm{~F}$ & 9.9 & 1.98 & -56.3 & -27.1 & -0.6 & -2.2 \\
\hline 3 & M & 16.9 & 3.96 & -59.4 & -15.1 & -15.5 & -6.5 \\
\hline 4 & M & 17.4 & 3.84 & -36.3 & -15.3 & -21.9 & -9.5 \\
\hline 5 & M & 14.2 & 2.89 & -49.0 & -6.3 & -37.5 & -30.8 \\
\hline 6 & $\mathrm{~F}$ & 15.5 & 2.78 & -1.1 & -0.9 & -1.1 & -8.4 \\
\hline 7 & $\mathrm{~F}$ & 14.3 & 2.91 & -15.8 & -1.6 & -10.9 & -0.7 \\
\hline 8 & $\mathrm{M}$ & 10.6 & 2.16 & -12.4 & -1.0 & -6.8 & 0.4 \\
\hline 9 & M & 14.0 & 3.27 & -8.8 & -2.0 & -8.5 & 1.8 \\
\hline 10 & $\mathrm{~F}$ & 12.9 & 2.27 & -69.9 & -17.1 & -11.8 & -11.2 \\
\hline 11 & $\mathrm{~F}$ & 14.5 & 1.91 & -43.5 & -46.6 & -24.1 & -5.9 \\
\hline 12 & $\mathrm{~F}$ & 10.0 & 1.55 & -26.3 & -7.2 & -17.7 & -6.0 \\
\hline 13 & M & 14.6 & 3.6 & -23.9 & -2.2 & -13.0 & -1.2 \\
\hline 14 & M & 12.8 & 1.88 & -10.5 & -2.6 & -7.1 & 0.9 \\
\hline 15 & $\mathrm{M}$ & 10.7 & 2.07 & -12.1 & -7.4 & -6.3 & -1.0 \\
\hline 16 & M & 12.0 & 2.46 & -8.4 & -2.1 & -8.7 & 0.7 \\
\hline 17 & $\mathrm{M}$ & 12.4 & 2.51 & -5.6 & -3.7 & -0.5 & 1.2 \\
\hline 18 & $\mathrm{~F}$ & 7.8 & 1.40 & -7.2 & 0.1 & -3.5 & -0.8 \\
\hline 19 & $\mathrm{M}$ & 12.9 & 2.47 & -24.9 & -2.0 & -6.0 & 0.6 \\
\hline 20 & $\mathrm{~F}$ & 14.8 & 3.14 & -33.3 & -0.3 & -8.4 & -2.6 \\
\hline 21 & $\mathrm{M}$ & 17.5 & 3.38 & -34.8 & -4.6 & -6.0 & -1.5 \\
\hline 22 & $\mathrm{~F}$ & 14.7 & 2.67 & -35.0 & -15.4 & -27.3 & -5.9 \\
\hline 23 & $\mathrm{~F}$ & 14.0 & 3.42 & -25.6 & -3.8 & -2.5 & -2.7 \\
\hline 24 & M & 16.3 & 4.43 & -31.6 & -8.3 & -25.5 & -4.5 \\
\hline 25 & $\mathrm{M}$ & 15.1 & 4.08 & -32.6 & -9.6 & -18.8 & -7.0 \\
\hline Mean & & 13.7 & 2.9 & -27.9 & -8.3 & -12.2 & -4.5 \\
\hline SD & & 2.6 & 0.9 & 18.1 & 10.4 & 9.5 & 6.7 \\
\hline
\end{tabular}

M: male; F: female; Salb.: salbutamol; Ned.: nedocromil.

nedocromil premedication (NV+SP) was comparable to that after salbutamol $(\mathrm{NP}+\mathrm{SV})$. However, as the latter started from a bronchodilator-induced higher postmedication (pre-CACh) level, the post-CACh values after nedocromil $(\mathrm{NV}+\mathrm{SP})$ and salbutamol $(\mathrm{NP}+\mathrm{SV})$ remained significantly different. Post-CACh measurements after the placebo combination $(\mathrm{NP}+\mathrm{SP})$ were significantly lower than those after any of the other premedications. All values improved again from the 3 to the $15 \mathrm{~min}$ post-CACh assessment, but most cross-sectional differences between the four different premedication regimens remained statistically significant.

The CACh-induced lung function changes are listed and statistically compared in table 3 and illustrated in figure 2. The biggest 3-min post-CACh change was observed after the placebo combination $(\mathrm{NP}+\mathrm{SP})$ and this change differed significantly from all the changes that were observed for the other premedication regimens. Changes from postmedication (pre-CACh)

Table 2. - Baseline, postmedication (pre-CACh), and post-CACh forced expiratory volume in one second (FEV1) measurements

\begin{tabular}{|c|c|c|c|c|}
\hline & \multicolumn{4}{|c|}{ FEV1 } \\
\hline & Baseline & Postmedication & $3 \mathrm{~min}$ post-CACh & $15 \mathrm{~min}$ post-CACh \\
\hline Placebo & $97.63 \pm 11.56$ & $97.50 \pm 11.55$ & $69.79 \pm 17.34$ & $78.26 \pm 16.40$ \\
\hline Ned. & $96.14 \pm 11.12$ & $97.98 \pm 11.96$ & $86.23 \pm 14.14$ & $93.94 \pm 11.35^{\oplus}$ \\
\hline Salb. & $96.96 \pm 12.37$ & $104.77 \pm 11.02^{\#}$ & $95.90 \pm 13.83^{\bullet}$ & $100.48 \pm 11.30^{\circ}$ \\
\hline Ned./Salb. & $96.95+11.85$ & $105.86+11.02^{\#}$ & $101.07+12.31^{\top}$ & $102.62+12.93^{\circ}$ \\
\hline Placebo versus Ned. & $\overline{\mathrm{NS}}$ & $\overline{N S}$ & $<0.001$ & $<0.001$ \\
\hline Placebo versus Salb. & NS & $<0.001$ & $<0.001$ & $<0.001$ \\
\hline Placebo versus Ned./Salb. & NS & $<0.001$ & $<0.001$ & $<0.001$ \\
\hline Ned. versus Salb. & NS & $<0.001$ & $<0.001$ & $<0.001$ \\
\hline Ned. versus Ned./Salb. & NS & $<0.001$ & $<0.001$ & $<0.001$ \\
\hline Salb. versus Ned./Salb. & NS & NS & $<0.05$ & NS \\
\hline
\end{tabular}

Data are presented as $\%$ pred mean \pm SD or as p-values. CACh: cold dry air challenge; Ned.: nedocromil; Salb.: salbutamol; NS: nonsignificant. \#: statistically significant difference from baseline to postmedication value; ": statistically significant difference from postmedication preCACh to postCACh value. 


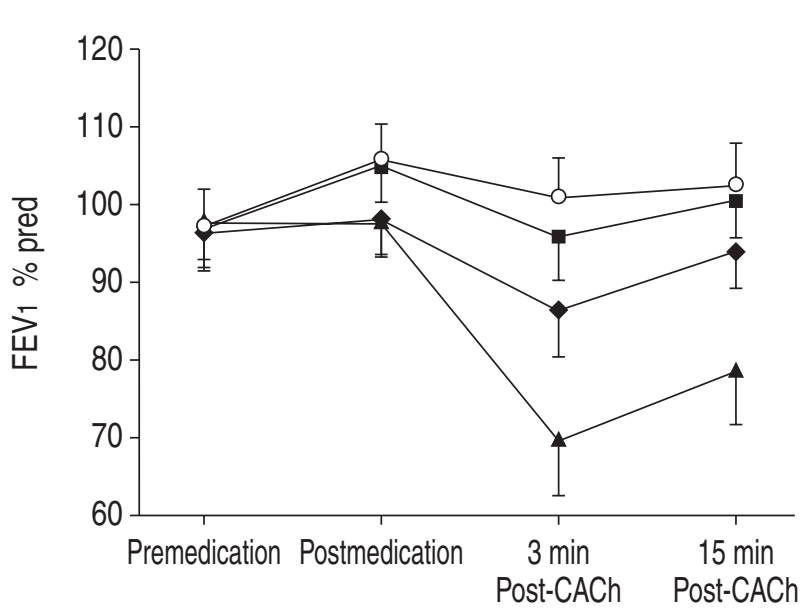

Fig. 1.-Baseline, postmedication (pre-cold dry air challenge $(\mathrm{CACh})$ and postchallenge values of forced expiratory volume in one second $\left(\mathrm{FEV}_{1}\right)$ of all four premedications ( $\boldsymbol{\Delta}$ : placebo; nedocromil; $\mathbf{\square}$ : salbutamol; $\bigcirc$ : salbutamol and nedocromil). Data are presented as $\%$ pred mean $\pm 95 \%$ confidence intervals.

values to those measured $15 \mathrm{~min}$ post-CACh were smaller, but the difference between the placebo combination $(\mathrm{NP}+\mathrm{SP})$ and all other premedications was retained. The smallest CACh-induced lung function change was observed after the combination of active drugs $(\mathrm{NV}+\mathrm{SV})$. This change differed significantly from that of the nedocromil premedication $(\mathrm{NV}+\mathrm{SP})$ measurements. When compared to the salbutamol premedication $(\mathrm{NP}+\mathrm{SV})$ changes, however, there was no significant difference for FEV1. Postmedication to 15 min post-CACh changes did not differ between any of the active medication regimens.

When defining protection against CACh-induced lung function changes as a fall of FEV1 that remained within the limits of normoreactivity, 21 of 25 patients $(84 \%)$ were protected with the combination of both active drugs $(\mathrm{NV}+\mathrm{SV}), 18(72 \%)$ with salbutamol $(\mathrm{NP}+\mathrm{SV}), 13(52 \%)$ with nedocromil $(\mathrm{NV}+\mathrm{SP})$, and five $(20 \%)$ with the placebo combination $(\mathrm{NP}+\mathrm{SP})$, respectively. The maximum individual $\mathrm{CACh}$-induced

Table 3. - Postchallenge fall of forced expiratory volume in one second (FEV 1 ) (\% pre-CACh)

\begin{tabular}{lcc}
\hline & \multicolumn{2}{c}{ FEV1 } \\
\cline { 2 - 3 } & $\begin{array}{c}3 \mathrm{~min} \\
\text { post-CACh }\end{array}$ & $\begin{array}{c}15 \mathrm{~min} \\
\text { post-CACh }\end{array}$ \\
\hline Placebo & $27.93 \pm 18.10$ & $19.30 \pm 17.17$ \\
Ned. & $12.15 \pm 9.46$ & $4.12 \pm 4.80$ \\
Salb. & $8.33 \pm 10.36$ & $3.99 \pm 5.91$ \\
Ned./Salb. & $4.49 \pm 6.67$ & $3.14 \pm 6.09$ \\
Placebo versus Ned. & $<0.001$ & $<0.001$ \\
Placebo versus Salb. & $<0.001$ & $<0.001$ \\
Placebo versus Ned./Salb. & $<0.001$ & $<0.001$ \\
Ned. versus Salb. & $\mathrm{NS}$ & $\mathrm{NS}$ \\
Ned. versus Ned./Salb. & $<0.001$ & $\mathrm{NS}$ \\
Salb. versus Ned./Salb. & $\mathrm{NS}$ & $\mathrm{NS}$ \\
\hline
\end{tabular}

Data are presented as mean \pm SD or as p-values. CACh: cold dry air challenge; Ned.: nedocromil; Salb.: salbutamol; NS: nonsignificant.

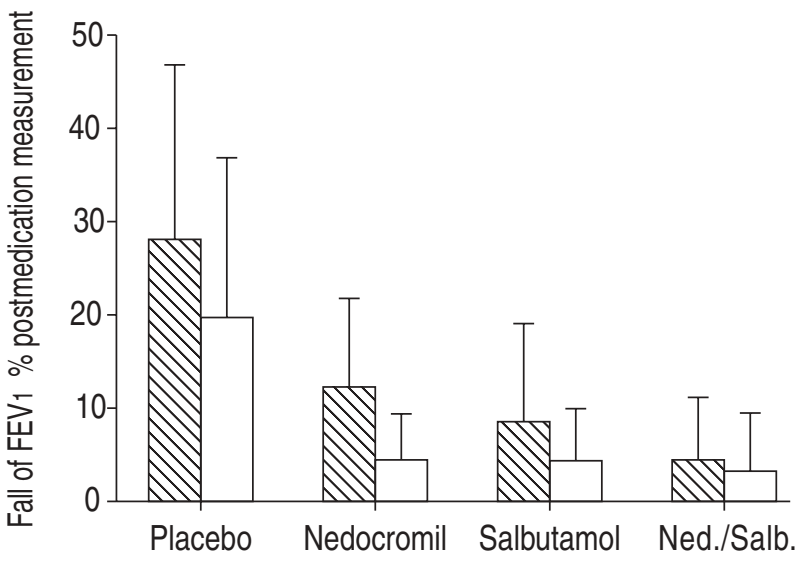

Fig. 2.- Per cent fall in forced expiratory volume in one second $(\mathrm{FEV} 1)$ after $3 \mathrm{~min}(\mathbb{\otimes})$ and $15 \mathrm{~min}(\square)$ after cold dry air challenge and different premedications. Data are presented as mean \pm SD. Ned.: nedocromil; Salb.: salbutamol.

fall of FEV1 was observed under the placebo combination $(\mathrm{NP}+\mathrm{SP})$ in 22 children, under nedocromil premedication $(\mathrm{NV}+\mathrm{SP})$ in one, under salbutamol premedication $(\mathrm{NP}+\mathrm{SV})$ in one, and under the combination of both active drugs $(\mathrm{NV}+\mathrm{SV})$ in one child, respectively.

\section{Discussion}

The present study shows that nedocromil offers significant protection against a CACh. However, this protection, both in terms of the mean protection and the number of patients with a normalised response, was somewhat less than the one achieved by salbutamol premedication. Maximum protection was observed with the combination of both active drugs, in keeping with a different mode of action.

This is the first study to directly compare the protective effects of nedocromil and a $\beta_{2}$-sympathomimetic premedication against isocapnic hyperpnoea-induced bronchoconstriction in children with bronchial asthma. This protective effect of nedocromil has previously been documented in several placebocontrolled paediatric [19-24] and adult studies [25-30]. One previous paediatric investigation compared salbutamol to a combination of nedocromil and salbutamol and found that both regimens offered substantial protection [31]. More recently, nedocromil was shown to protect against the consequences of epithelial lining fluid hyperosmolarity, by interfering with regulatory cell volume changes [9]. As indicated by bronchoalveolar lavage findings, such cell volume changes lead to EIB via release of various mediators from different cell systems [10]. Whether these mediators are only responsible for bronchoconstriction or also have some pro-inflammatory effects, remains unclear. However, late asthmatic reactions after strenuous physical exercise [30, 32] and the recent observation of an increased asthma prevalence in competitive track and field athletes as well as swimmers [33, 34], suggest that repeated exercise-induced hyperpnoea might have the potential to induce the 
manifestation or exacerbation of bronchial asthma. Speculatively, this might be understood as the long-term consequence of the above-mentioned mediator release.

If this was a valid hypothesis, any premedication with sympathomimetic bronchodilators could be seen as a management strategy with limited therapeutic long-term value. By interfering with the constriction of bronchial smooth muscle, bronchodilators will predominantly ameliorate the last step of the reaction cascade that leads to EIB, while having only a little effect on the preceding release of mediators. From a long-term perspective, this might be disadvantageous, as it could allow for ongoing perpetuation of the bronchial inflammation while preventing any perceivable warning by immediate bronchoconstriction. This concern finds some support in the observation of more severe EIB with the chronic daily use of sympathomimetic bronchodilators [35]. In addition, it has been speculated that such chronic use of $\beta_{2}$-adrenoceptor agonists, which stimulates the secretion of chloride ions, might cause an accelerated loss of cell volume, thus facilitating the trigger mechanism for EIB $[8,9]$.

As shown by the present study, nedocromil significantly reduces both the occurrence and the severity of EIB. In fact, it affected approximately two thirds of the protection that was observed after premedication with a $\beta_{2}$-sympathomimetic bronchodilator. As nedocromil is thought to interfere with the development of EIB by reducing initially occurring cell volume changes [9], it should also ameliorate the consecutive mediator release into the respiratory mucosa. However, this second therapeutic effect, which should be beneficial in the long term, remains speculative at present, as it is based on theoretical reasoning only and is not yet supported by relevant study results. Thus, it would be interesting to follow up the present findings with a bronchoalveolar lavage project, comparing dry air hyperpnoea-induced mediator release after nedocromil and placebo premedication. For obvious ethical reasons, such an investigation should not be performed in paediatric patients but rather in adult volunteers with bronchial asthma.

The findings of the present study, in combination with the above theoretical considerations, might have some practical implications for the clinical management of EIB in susceptible asthma patients. In the long term, patients who are sufficiently protected by nedocromil might benefit from using nedocromil rather than sympathomimetic bronchodilators for premedication against EIB. The other subgroup, i.e. patients who still require a $\beta_{2}$-adrenoceptor agonist for sufficient amelioration of EIB, could also receive some long-term benefit from combining the $\beta_{2}$-adrenoceptor agonist with nedocromil. Clearly, as these speculations are based on the present study results, they only pertain to the premedication routine for prevention of EIB. Any such premedication, however, should be seen as an adjunct and not as a substitute for the basic routine of an anti-inflammatory long-term medication.

One interesting side product of this study is the finding of a high prevalence of airway hyperresponsiveness in a group of paediatric asthma patients that were considered to be well stabilised by long-term medication, as judged by routine clinical and lung function criteria. Others have made similar observations and have shown that monitoring of anti-asthma management by additional measurements of nonspecific bronchial responsiveness can lead to a significantly better long-term outcome in terms of exacerbation frequency, lung function and bronchial histology [36]. This raises the question as to whether the assessment of bronchial responsiveness, as a surrogate marker of bronchial inflammation, should be included in the routine monitoring of asthma patients.

The present study used a CACh, i.e. the voluntary hyperpnoea of cold and absolutely dry air, as a laboratory model for EIB. Earlier work has shown that exercise-induced hyperpnoea is responsible for triggering EIB [3-5]. CACh is meanwhile a wellstandardised bronchial provocation technique that has been used mainly as a paediatric research tool [13-15]. As the trigger mechanism can be dimensioned with considerable accuracy in $\mathrm{CACh}$, the use of this technique had the advantage of highly-reproducible stimulus for the series of four challenges which had to be performed in the present study.

In conclusion, this study showed that nedocromil offers substantial protection against hyperpnoeainduced bronchoconstriction, both in terms of reducing the dimension of the reaction and of normalising bronchial responsiveness in some asthma patients. However, the protection offered by salbutamol premedication remained superior to that after nedocromil. Maximum protection was most often achieved with the combination of both substances. As nedocromil interferes with the first step of the reaction cascade that leads to exercise- or hyperpnoea-induced bronchoconstriction, it might have long-term advantages over salbutamol by more potently reducing the pro-inflammatory mediator load on the bronchial mucosa. Whether this calls for a change in the premedication routine against exercise-induced bronchoconstriction or not, should be subject to further investigation.

Acknowledgements. The authors acknowledge the assistance of J. Haas with the statistical analysis and of S. Kupka in providing the placebo medication.

\section{References}

1. Godfrey S, Springer C, Noriski N, et al. Exercise but not metacholine differentiates asthma from chronic lung disease in children. Thorax 1991; 46: 488-492.

2. Custovic A, Arifhodzic N, Robinson A, et al. Exercise testing revisited: the response to exercise in normal and atopic children. Chest 1994; 105: 1127-1132.

3. Strauss RH, McFadden ER Jr, Ingram RH, et al. Enhancement of exercise-induced asthma by cold air. $N$ Engl J Med 1977; 297: 743-747.

4. Strauss $\mathrm{RH}, \mathrm{McFadden} \mathrm{ER} \mathrm{Jr}$, Ingram $\mathrm{RH}$, et al. Influence of heat and humidity on the airway obstruction induced by exercise in asthma. J Clin Invest 1978; 61: 433-440. 
5. Deal EC Jr, McFadden ER Jr, Ingram $\mathrm{RH}$, et al. Airway responsiveness to cold air and hyperpnea in normal subjects and in those with hayfever and asthma. Am Rev Respir Dis 1980; 121: 621-638.

6. Anderson SD, Schoeffel RE, Follet R, et al. Sensitivity to heat and water loss at rest and during exercise in asthmatic patients. Eur J Respir Dis 1982; 63: 459-471.

7. Freed AN. Models and mechanisms of exerciseinduced asthma. Eur Respir J 1995; 8: 1770-1785.

8. Gschwentner M, Susanna A, Schmarda A, et al. ICln: a chloride channel paramount for cell volume regulation. J Allergy Clin Immunol 1996; 98: S98-S101.

9. Anderson SD, Rodwell LT, Daviskas E, et al. The protective effect of nedocromil sodium and other drugs on airway narrowing provoked by hyperosmolar stimuli. A role for the airway epithelium. J Allergy Clin Immunol 1996; 98: S124-S134.

10. Pliss LB, Ingenito EP, Ingram RH, et al. Assessment of bronchoalveolar cell and mediator response to isocapnic hyperpnea in asthma. Am Rev Respir Dis 1990; 142: 73-78.

11. Godfrey S, König P. Suppression of exercise-induced asthma by salbutamol, theophylline, atropine, cromolyn, and placebo in a group of asthmatic children. Pediatrics 1975; 56: 930-934.

12. Henriksen J, Agertoft ML, Pedersen S. Protective effect and duration of action of inhaled formoterol and salbutamol on exercise-induced asthma in children. J Allergy Clin Immunol 1992; 89: 1176-1182.

13. Zach MS, Polgar G, Kump H, et al. Cold air challenge of airway hyperreactivity in children: practical application and theoretical aspects. Pediatr Res 1984; 18: 469-478.

14. Zach MS, Polgar G. Cold air challenge of airway hyperreactivity in children: Dose-response interrelation with a reaction plateau. J Allergy Clin Immunol 1987; 80: 9-17.

15. Zach MS. Measurement of bronchial responsiveness by non-pharmacological challenges: methodological issues. Pediatr Allergy Immunol 1996; 7: Suppl. 9, 2833.

16. National Heart, Lung and Blood Institute, National Institutes of Health, Bethesda, Maryland. International Consensus report on diagnosis and treatment of asthma. Eur Respir J 1992; 5: 601-641.

17. Quanjer PH, Tammeling GJ, Cotes JE, et al. Lung volumes and forced ventilatory flows. Report working party standardization of lung function tests, European Coal and Steel Community. Official statement of the European Respiratory Society. Eur Respir J 1993; 6: Suppl. 16, 5-40.

18. Hibbert ME, Lannigan A, Landau LJ, et al. Lung function values from a longitudinal study of healthy children and adolescents. Pediatr Pulmonol 1989; 7 : 101-109.

19. Chudry N, Correa F, Silverman M. Nedocromil sodium and exercise-induced asthma. Arch Dis Child 1987; 62: 412-414.

20. Henriksen JM. Effect of nedocromil sodium on exercise-induced bronchoconstriction in children. Allergy 1988; 43: 449-453.

21. Boner AL, Vallone G, Bennati D. Nedocromil sodium in exercise-induced bronchoconstriction in children. Ann Allergy 1989; 62: 38-41.
22. Wönne R, Monkhoff M, Ahrens P, et al. Study of the protective action of nedocromil sodium with bronchial cold-air provocation in children with bronchial asthma. Pneumologie 1990; 44: 1193-1195.

23. Novembre E, Frongia GF, Veneruso G, et al. Inhibition of exercise-induced asthma (EIA) by nedocromil sodium and sodium cromoglycate in children. Pediatr Allergy Immunol 1994; 5: 107-110.

24. Oseid S, Mellbye E, Hem E. Effect of nedocromil sodium on exercise-induced bronchoconstriction exacerbated by inhalation of cold air. Scand J Med Sci Sport 1995; 5: 88-93.

25. König P, Hordvik NL, Kreutz C. The preventive effect and duration of action of nedocromil sodium and cromolyn sodium on exercise-induced asthma (EIA) in adults. $J$ Allergy Clin Immunol 1987; 79: 64 68.

26. Bundgaard A, Enehjelm SD, Schmidt A. A comparative study of the effects of two different doses of nedocromil sodium and placebo given by pressurised aerosol in exercise-induced bronchoconstriction. Allergy 1988; 43: 493-496.

27. Vilsvik J, Schaaning J. A comparative study of the effect of three doses of nedocromil sodium and placebo given by pressurized aerosol to asthmatics with exercise-induced bronchoconstriction. Ann Allergy 1988; 61: 367-370.

28. Albazzaz MK, Neale MG, Patel KR. Dose-response study of nebulised nedocromil in exercise-induced asthma. Thorax 1989; 44: 816-819.

29. Morton AR, Ogla SL, Fitch KD. Effects of nedocromil sodium, cromolyn sodium, and a placebo in exercise-induced asthma. Ann Allergy 1992; 68: 143148.

30. Speelberg B, Verhoeff NPLG, van den Berg NJ, et al. Nedocromil sodium inhibits the early and late asthmatic response to exercise. Eur Respir J 1992; 5: 430437.

31. De Benedictis FM, Tuteri G, Pazzelli $P$, et al. Combination drug therapy for prevention of exerciseinduced bronchoconstriction in children. Ann Allergy Asthma Immunol 1998; 80: 352-356.

32. Crimi E, Balbo A, Milanese M, et al. Airway inflammation and occurence of delayed bronchoconstriction in exercise-induced asthma. Am Rev Respir Dis 1992; 146: 507-512.

33. Larsson $\mathrm{K}$, Ohlsen $\mathrm{P}$, Larsson L, et al. High prevalence of asthma in cross country skiers. BMJ 1993; 307: 1326-1329.

34. Tikkanen HO, Helenius IJ, Haahtela T. Prevalence of asthma and allergy in track and field athletes and swimmers in Finnland. In: Carlsen KH, Ibsen TB, eds. Exercise-induced asthma and sports in asthma. 1st Edn. Copenhagen, Munksgaard, 1999; pp. 57-60.

35. Inman MD, $\mathrm{O}^{\prime}$ Byrne $\mathrm{PM}$. The effect of regular inhaled albuterol on exercise-induced bronchoconstriction. Am J Respir Crit Care Med 1996; 153: 6569.

36. Sont JK, Willems LNA, Bel EH, et al. Clinical control and histopathologic outcome of asthma when using airway hyperresponsiveness as an additional guide to long-term treatment. Am J Respir Crit Care Med 1999; 159: 1043-1051. 